Research Article

\title{
Study on Vortex-Induced Vibration of Deep-Water Marine Drilling Risers in Linearly Sheared Flows in consideration of Changing Added Mass
}

\author{
Guanghai Gao $\mathbb{D}^{1},{ }^{1}$ Xiao Cong, ${ }^{2}$ Yunjing Cui ${ }^{D},{ }^{3}$ and Xingqi Qiu $\mathbb{D}^{1}$ \\ ${ }^{1}$ College of New Energy, China University of Petroleum (East China), Qingdao 266580, China \\ ${ }^{2}$ Shandong Special Equipment Inspection Institute Co., Ltd., Jinan 250101, China \\ ${ }^{3}$ College of Mechanical and Electronic Engineering, China University of Petroleum (East China), Qingdao 266580, China
}

Correspondence should be addressed to Yunjing Cui; cuiyj@upc.edu.cn

Received 17 August 2019; Accepted 9 January 2020; Published 13 February 2020

Academic Editor: Leonardo Acho

Copyright (C) 2020 Guanghai Gao et al. This is an open access article distributed under the Creative Commons Attribution License, which permits unrestricted use, distribution, and reproduction in any medium, provided the original work is properly cited.

In order to more accurately predict the coupled in-line and cross-flow vortex-induced vibration (VIV) response of deep-water marine drilling risers in linearly sheared flows, an improved three-dimensional time-domain coupled model based on van der Pol wake oscillator models was established in this paper. The impact of the in-line and cross-flow changing added mass coefficients was taken into account in the model. The finite element, Newmark- $\beta$, and Newton-Raphson methods were adopted to solve the coupled nonlinear partial differential equations. The entire numerical solution process was realized by a self-developed program based on MATLAB. Comparisons between the numerical calculations and the published experimental tests showed that the improved model can more accurately predict some main features of the coupled in-line and cross-flow VIV of long slender flexible risers in linearly sheared flows to some extent. The coupled in-line and cross-flow VIV of a real-size marine drilling riser, usually used in the deep-water oil/gas industry in the South China Sea, was analyzed. The influence of top tension force and seawater flow speed, as well as platform heave amplitude and frequency, on the riser in-line and cross-flow VIV was also discussed. The results show that the platform heave motion increases the VIV displacements and changes the magnitudes of peak frequencies as well as the components of frequencies. The platform heave motion also has a significant influence on the vibration modes of the middle and upper sections of the riser. The impact level of each factor on the in-line and cross-flow VIV response of the riser is different. The improved model and the results of this paper can be used as a reference for the engineering design of deep-water marine drilling risers.

\section{Introduction}

Long slender flexible cylinders such as marine drilling risers are widely used in the deep-water oil/gas industry. The inline (IL) and cross-flow (CF) vortex-induced vibrations (VIV) will occur when seawater flows through risers. It is widely accepted that accurately predicting the main features of the coupled in-line and cross-flow VIV response is the key to the engineering design of deep-water marine drilling risers. The detailed mechanism, related research methods, and some main features of the coupled in-line and cross-flow VIV response of long slender flexible cylinders have been described in some review literature $[1,2]$.
For a long time, semiempirical models based on wake oscillator models have been widely used in the prediction of VIV response of short/long cylinders in uniform/sheared flows due to their superiority. The nonlinear dynamic oscillators are adopted to predict the main features of vortex shedding in the wake region of risers. Based on the van der Pol equation, Bishop and Hassan [3] first put forward the specific expression of the wake oscillator model. Then, wake oscillator models have been continuously improved by some researchers [4-13]. Based on wake oscillator models, some studies have analyzed the coupled in-line and cross-flow VIV response of long slender flexible cylinders in uniform flows [14-16], and some scholars have also focused their attention 
on the study of coupled in-line and cross-flow VIV response of long slender flexible cylinders in sheared flows [17-23]. Leclercq and de Langre [24] also studied the VIV response of cylinders with large in-line bending deformation.

Added mass coefficients play a significant role in the prediction of the VIV response of long slender flexible risers, especially in sheared flows. Wang et al. [25] formulated the semiempirical formulas of cross-flow added mass coefficient of flexibly mounted rigid circular cylinders in lock-in situations. Aronsen [26] and Larsen et al. [27] developed the simplified in-line and cross-flow added mass coefficient models, respectively. These simplified models are related to nondimensional frequency. Yuan et al. [28] studied the inline and cross-flow VIV response of small-scale and relatively long tensioned risers in uniform flows based on these simplified added mass coefficient models and force decomposition models. Song et al. [29] developed the in-line and cross-flow added mass coefficients of a small-scale top tensioned riser in uniform flows through the least-squares method based on experimental tests.

Floating drilling platforms are widely used in the deepwater oil/gas drilling industry. Floating drilling platforms usually have larger heave motions, and this will inevitably cause the riser axial tension force to change constantly with time. Time-varying axial tension force will affect the in-line and cross-flow VIV response of risers to some extent. Franzini et al. [30] studied the cross-flow VIV response of a small-scale flexible cylinder through experimental tests in consideration of the time-varying axial tension force. Based on force decomposition models, Yuan et al. [31] studied the influence of timevarying axial tension force on cross-flow VIV response of long flexible risers in uniform flows through numerical simulation. Based on force decomposition models, Zhang et al. [32] numerically studied the in-line and cross-flow VIV response of a small-scale riser in uniform flows in consideration of the time-varying axial tension force. Zhang et al. [33] numerically studied the influence of time-varying axial tension force on the in-line and cross-flow VIV response of a flexible marine riser in uniform flows based on wake oscillator and force decomposition models. Zhang et al. [33] studied the VIV response of a flexible fluid-conveying marine riser subjected to axial harmonic tension. He et al. [34] studied the VIV response of a pipe subjected to unsynchronized support motions.

With a review of the previous research, some researchers have formulated various models to study the VIV response of different structures in different situations. Based on experimental tests and numerical simulations, the main features of VIV of different structures have been mastered to some extent. However, so far, there are still some issues that require further investigation. When the riser with a large aspect ratio (length/diameter) is in sheared flows, the in-line and cross-flow added mass coefficients vary continuously along the riser length due to the change of current velocity. The existing semiempirical models based on wake oscillator models usually simplify the value of the added mass coefficient to 1.0 when predicting the in-line and cross-flow VIV response of risers in sheared flows. However, this affects the prediction accuracy of these models, making the errors between the prediction results and the actual ones relatively large. Besides, the effect of time-varying axial tension force on the VIV response of large aspect ratio and small-scale risers is different. At present, there are few published papers on the study of the coupled in-line and cross-flow VIV response of large aspect ratio risers in sheared flows in consideration of time-varying axial tension force. In particular, there are fewer published papers on this study based on wake oscillator models.

Given this, an improved three-dimensional time-domain coupled model in consideration of the changing in-line and cross-flow added mass coefficients is established in this paper. The model is based on wake oscillator models. The coupled in-line and cross-flow VIV response of a deep-water marine drilling riser in linearly sheared flows is studied in this paper based on the improved model. The effects of the top tension force and seawater flow speed, as well as the platform heave amplitude and frequency, on the riser VIV response are also discussed.

\section{Theoretical Models}

2.1. Structural Model. Two-end pined Euler-Bernoulli beam model is used to simulate deep-water marine drilling risers. A Cartesian coordinate system is defined, in which the $x$ axis is parallel to the direction of seawater flow and the $z$ axis is parallel to the axial direction of the undeformed riser. Figure 1 shows the schematic model of marine drilling risers.

Although the aspect ratio and the lateral bending displacement of deep-water marine drilling risers are large, the risers lateral bending strain is small. The geometric nonlinearity has little effect on the dynamic response of the risers. Thus, the motion equations of marine drilling risers can be expressed as follows [18]:

$$
\begin{aligned}
& E I \frac{\partial^{4} x(z, t)}{\partial z^{4}}-\frac{\partial}{\partial z}\left(T(z, t) \frac{\partial x(z, t)}{\partial z}\right)+\bar{m} \frac{\partial^{2} x(z, t)}{\partial t^{2}} \\
& +\bar{c} \frac{\partial x(z, t)}{\partial t}=F_{x}(z, t), \\
& E I \frac{\partial^{4} y(z, t)}{\partial z^{4}}-\frac{\partial}{\partial z}\left(T(z, t) \frac{\partial y(z, t)}{\partial z}\right)+\bar{m} \frac{\partial^{2} y(z, t)}{\partial t^{2}} \\
& \quad+\bar{c} \frac{\partial y(z, t)}{\partial t}=F_{y}(z, t),
\end{aligned}
$$

where $E$ is the elastic modulus; $I$ is the axial moment of inertia; $T(z, t)$ is the time-varying axial tension force; $\bar{m}$ is the equivalent mass of per-unit-length riser; $\bar{c}$ is the equivalent damping coefficient; and $F_{x}(z, t)$ and $F_{y}(z, t)$ are the in-line and cross-flow fluctuating hydrodynamic forces acting on risers, respectively.

The time-varying axial tension force of marine drilling risers can be expressed as follows [35]:

$$
T(z, t)=T_{\text {top }}-\int_{z}^{H} w \mathrm{~d} z+K \widetilde{A} \sin (\widetilde{\Omega} t),
$$




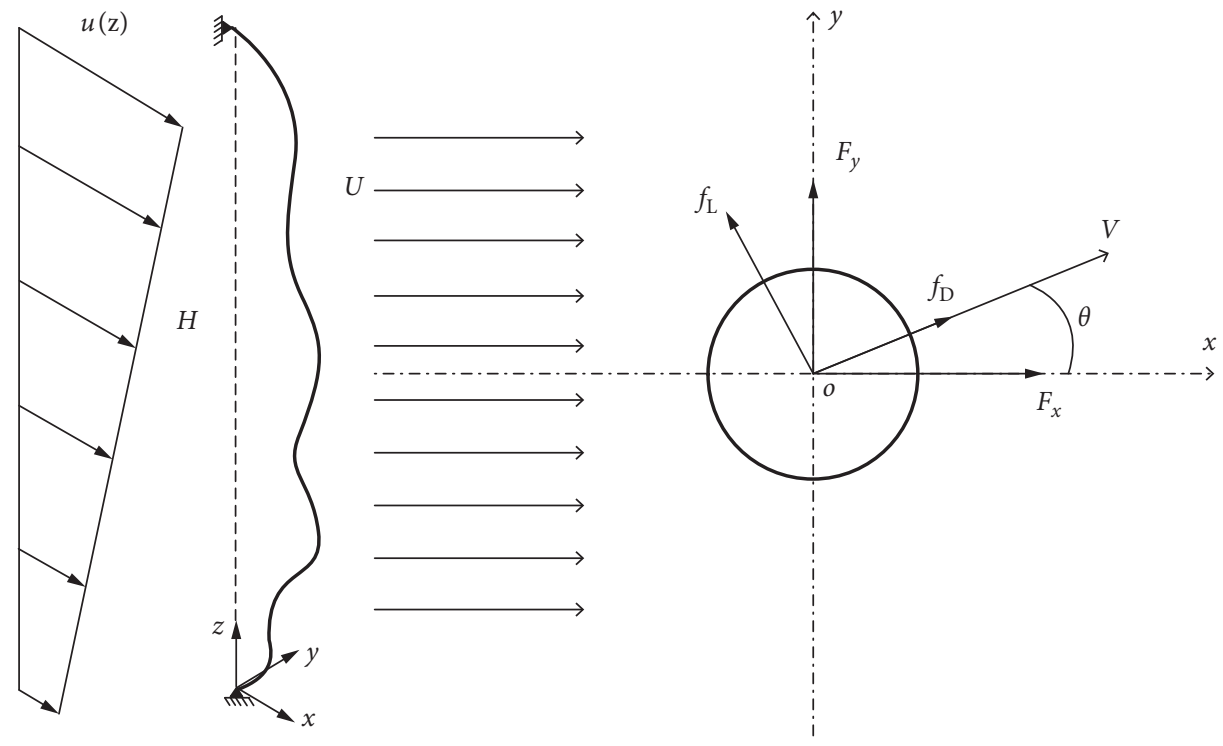

FIgURE 1: Schematic model of marine drilling risers.

where $T_{\text {top }}$ is the top tension force $\left(T_{\text {top }}=f_{\text {top }} w H\right) ; f_{\text {top }}$ is the top tension force coefficient; $w$ is the wet weight of perunit-length riser; $H$ is the water depth; $K$ is the equivalent spring stiffness of heave compensators $\left(K=w H / A_{c}\right) ; A_{c}$ is the critical amplitude associated with heave compensators (usually set as $10 \mathrm{~m}$ ); and $\widetilde{A}$ and $\widetilde{\Omega}$ are the platform heave amplitude and frequency, respectively.

The first two terms at the right end of equation (3) are the time-independent axial tension force at different points of the riser caused by the top tension force and the riser wet weight. The third term at the right end of equation (3) is the time-dependent axial tension force excited by the platform heave motion.

The wet weight and the related mass of per-unit-length riser can be expressed as follows:

$$
\left\{\begin{array}{l}
w=\left(m_{\mathrm{r}}+m_{\mathrm{f}}-m_{\mathrm{d}}\right) g \\
\bar{m}=m_{\mathrm{r}}+m_{\mathrm{f}}+m_{\mathrm{a}}, \\
m_{\mathrm{r}}=\frac{\pi \rho_{\mathrm{r}}\left(D^{2}-d^{2}\right)}{4}, \\
m_{\mathrm{f}}=\frac{\pi \rho_{\mathrm{f}} d^{2}}{4} \\
m_{\mathrm{d}}=\frac{\pi \rho_{\mathrm{w}} D^{2}}{4}, \\
m_{\mathrm{a}}=\frac{C_{\mathrm{a}} \pi \rho_{\mathrm{w}} D^{2}}{4}
\end{array}\right.
$$

where $m_{\mathrm{r}}, m_{\mathrm{f}}, m_{\mathrm{a}}$, and $m_{\mathrm{d}}$ are the mass of per-unit-length riser, internal fluid, external added seawater, and external displaced seawater, respectively; $g$ is the gravity acceleration; $\rho_{\mathrm{r}}, \rho_{\mathrm{f}}$, and $\rho_{\mathrm{w}}$ are the densities of the riser, internal fluid, and external seawater, respectively; $D$ and $d$ are the outer and inner diameters of the riser, respectively; and $C_{a}$ is the added mass coefficient.

The formulas of the equivalent damping coefficients can be expressed as follows $[6,18]$ :

$$
\left\{\begin{array}{l}
\bar{c}=c_{\mathrm{s}}+c_{\mathrm{f}}, \\
c_{\mathrm{f}}=\gamma \Omega_{\mathrm{f}} \rho_{\mathrm{w}} D^{2},
\end{array}\right.
$$

where $c_{\mathrm{s}}$ is the structural damping coefficient; $c_{\mathrm{f}}$ is the fluid damping coefficient; $\gamma$ is the nondimensional damping coefficient; and $\Omega_{\mathrm{f}}$ is the vortex shedding angular frequency.

The nondimensional damping coefficient can be expressed as follows [6]:

$$
\gamma=\frac{\bar{C}_{D}}{4 \pi S_{t}},
$$

$\bar{C}_{D}$ is the mean drag force coefficient of vibrating risers, and it can be expressed as follows [6]:

$$
\bar{C}_{\mathrm{D}}=\bar{C}_{\mathrm{D} 0}\left(1+\frac{2 \bar{y}}{D}\right) \text {, }
$$

where $\bar{C}_{\mathrm{D} 0}$ is the mean drag force coefficient of stationary risers and $\bar{y}$ is the cross-flow VIV amplitude of vibrating risers.

The vortex shedding angular frequency can be expressed as follows [18]:

$$
\Omega_{\mathrm{f}}=\frac{2 \pi S_{\mathrm{t}} u(z)}{D}
$$

where $S_{\mathrm{t}}$ is the Strouhal number and $u(z)$ is the seawater flow speed.

In linearly sheared flows, the seawater flow speed at different water depths can be expressed as follows:

$$
u(z)=u_{\mathrm{b}}+\frac{\left(u_{\mathrm{s}}-u_{\mathrm{b}}\right) z}{H},
$$


where $u_{\mathrm{s}}$ and $u_{\mathrm{b}}$ are the sea surface and bottom seawater flow speed, respectively.

2.2. Added Mass Coefficients. Added mass coefficients play a significant role in the in-line and cross-flow VIV response of deep-water marine drilling risers. According to previous studies, added mass coefficients are mainly determined by the nondimensional VIV amplitude and frequency of risers. The formulas of the nondimensional VIV amplitude and frequency are expressed as follows:

$$
\left\{\begin{array}{l}
A^{*}=\frac{A}{D} \\
f_{\mathrm{r}}=\frac{f D}{u},
\end{array}\right.
$$

where $A$ is the riser in-line/cross-flow VIV amplitude and $f$ is the riser in-line/cross-flow VIV frequency.

According to research results, the effect of nondimensional VIV frequency on added mass coefficients is much larger than that of nondimensional VIV amplitude [26, 27]. When ignoring the effect of nondimensional VIV amplitude, the simplified in-line and cross-flow added mass coefficient models were proposed by Aronsen et al. [26] and Larsen et al. [27], respectively. The simplified in-line and cross-flow added mass coefficient models are shown in Figure 2. In this paper, these simplified added mass coefficient models are adopted to predict the coupled in-line and cross-flow VIV response of deep-water marine drilling risers in linearly sheared flows. The initial values of the in-line and cross-flow added mass coefficients are set to 1.0 in the present study.

2.3. Hydrodynamic Forces. According to previous studies $[6,18]$, the in-line and cross-flow hydrodynamic forces acting on risers can be expressed as follows:

$$
\begin{aligned}
& F_{x}(z, t)=F_{\mathrm{D}}-F_{\mathrm{L}} \frac{\partial y}{\partial t}, \\
& F_{y}(z, t)=F_{\mathrm{L}}+F_{\mathrm{D}} \frac{\partial y}{\partial t},
\end{aligned}
$$

where $F_{\mathrm{D}}$ is the in-line VIV drag force and $F_{\mathrm{L}}$ is the crossflow VIV lift force.

Based on the Morison equation, the VIV drag and lift forces acting on per-unit-length riser can be expressed as follows [18]:

$$
\begin{gathered}
F_{\mathrm{D}}=0.5 C_{\mathrm{D}} \rho_{\mathrm{w}} D u(z)^{2}, \\
F_{\mathrm{L}}=0.5 C_{\mathrm{L}} \rho_{\mathrm{w}} D u(z)^{2},
\end{gathered}
$$

where $C_{\mathrm{D}}$ and $C_{\mathrm{L}}$ are the time-varying VIV drag and lift force coefficients of vibrating risers, respectively.

2.4. Wake Oscillator Models. According to wake oscillator models $[6,18], C_{\mathrm{D}}$ and $C_{\mathrm{L}}$ can be simulated by the timevarying fluid vortex variables $p$ and $q$ :

$$
\begin{aligned}
\ddot{p}+2 \varepsilon_{x} \Omega_{\mathrm{f}}\left(p^{2}-1\right) \dot{p}+4 \Omega_{\mathrm{f}}^{2} p & =\frac{A_{x}}{D} \frac{\partial^{2} x(z, t)}{\partial t^{2}}, \\
\ddot{q}+\varepsilon_{y} \Omega_{\mathrm{f}}\left(q^{2}-1\right) \dot{q}+\Omega_{\mathrm{f}}^{2} q & =\frac{A_{y}}{D} \frac{\partial^{2} y(z, t)}{\partial t^{2}},
\end{aligned}
$$

where $p=2 C_{\mathrm{D}} / C_{\mathrm{D} 0}$ and $q=2 C_{\mathrm{L}} / C_{\mathrm{L} 0} ; C_{\mathrm{D} 0}$ and $C_{\mathrm{L} 0}$ are the VIV drag and lift force coefficients of stationary risers, respectively; and $\varepsilon_{x}, \varepsilon_{y}, A_{x}$, and $A_{y}$ are nondimensional empirical coefficients.

2.5. Boundary Conditions. In the actual deep-water oil/gas drilling engineering, the top end of the riser is connected to the platform through the heave compensator system to ensure that the riser does not produce large vibration displacement in the axial direction. Thus, the riser boundary conditions can be expressed as follows:

$$
\begin{cases}x(0, t)=y(0, t)=0 ; & x(H, t)=y(H, t)=0, \\ \frac{\partial^{2} x(0, t)}{\partial z^{2}}=\frac{\partial^{2} y(0, t)}{\partial z^{2}}=0 ; & \frac{\partial^{2} x(H, t)}{\partial z^{2}}=\frac{\partial^{2} y(H, t)}{\partial z^{2}}=0 .\end{cases}
$$

2.6. Initial Conditions. At the initial moment $(t=0)$, the vibration displacement and velocity of the riser are assumed to be zero, the values of fluid vortex variables $p$ and $q$ are set to 2 , and their velocities are assumed to be zero. Therefore, the initial conditions can be expressed as follows:

$$
\begin{cases}x(z, 0)=y(z, 0)=0, & \frac{\partial x(z, 0)}{\partial t}=\frac{\partial y(z, 0)}{\partial t}=0, \\ p=q=2, & \frac{\partial p}{\partial t}=\frac{\partial q}{\partial t}=0 .\end{cases}
$$

2.7. Values of Nondimensional Empirical Coefficients. According to $[5,6,18]$, the values of nondimensional empirical coefficients are given in Table 1.

\section{Numerical Solution Methods}

The coupled form of equations (1) to (16) is nonlinear partial differential equations with variable coefficients. Some coefficients in the coupled equations change continuously along with the spatial position, and some coefficients change continuously with time. The coupled equations are very complicated and the analytical solution cannot be obtained. Thus, the numerical solution methods are used in the present study to solve the coupled equations.

The Galerkin-type finite element method is used to conduct the spatial discretization of the coupled equations. Based on the parameters of the riser and seawater, as well as the boundary and initial conditions, the Hermite cubic interpolation functions are used to obtain the system flexural stiffness matrix, geometric stiffness matrix, mass matrix, and 


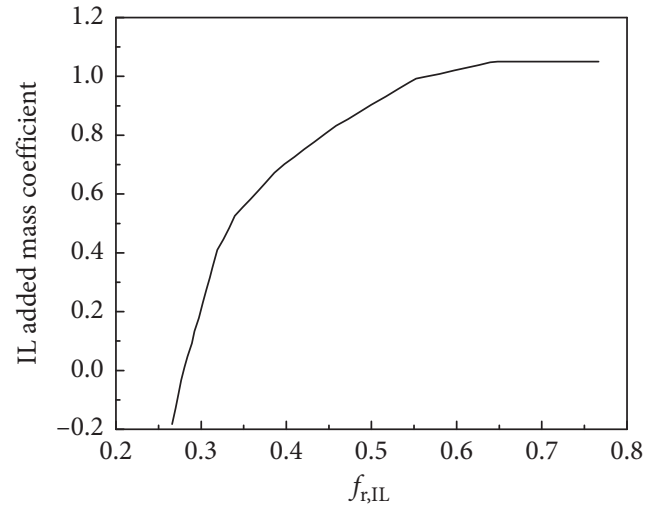

(a)

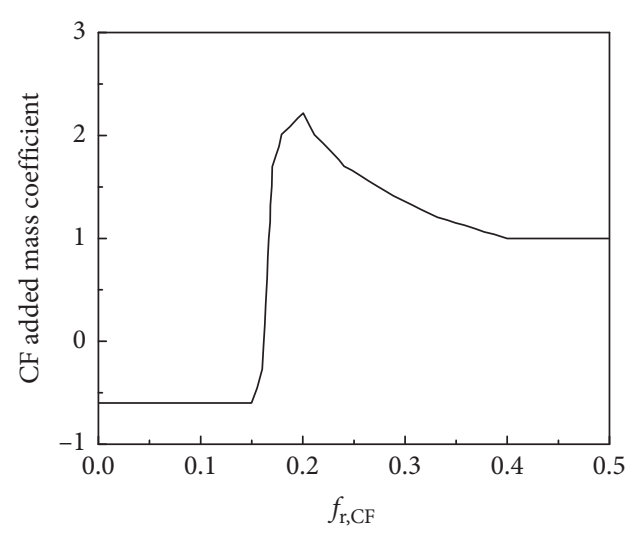

(b)

FIgURE 2: Simplified curves of (a) in-line and (b) cross-flow added mass coefficient [26, 27].

TABLe 1: Values of nondimensional empirical coefficients.

\begin{tabular}{lc}
\hline Empirical coefficients & Values \\
\hline$S_{\mathrm{t}}$ & 0.17 \\
$\bar{C}_{\mathrm{D} 0}$ & 1.2 \\
$C_{\mathrm{D} 0}$ & 0.1 \\
$C_{\mathrm{L} 0}$ & 0.3 \\
$A_{x}, A_{y}$ & 12 \\
$\varepsilon_{x}, \varepsilon_{y}$ & 0.3 \\
\hline
\end{tabular}

damping matrix. Due to the uncertainty of the riser damping coefficient, the Rayleigh damping theory is adopted in this paper to obtain the structural damping matrix. It is assumed that the vibration shape functions of wake oscillators are trigonometric functions. Then the wake oscillators are used to obtain the damping matrix of the fluid and the dynamic load matrix at the initial moment. The specific expressions of the finite element method can be found in [36], and the specific solution process of wake oscillator models can be found in $[5,6]$.

The Newmark- $\beta$ method is used to solve the coupled equations in the time domain. In each time step, the Newton-Raphson iterative method is used to solve the nonlinear equations. The system geometric stiffness matrix, mass matrix, damping matrix, dynamic load matrix, and natural vibration frequency are all constantly updated at each time step. Since the Newmark- $\beta$ and Newton-Raphson iterative methods are relatively mature, this paper no longer describes their specific expressions. The entire numerical solution process is realized by a self-developed program based on MATLAB.

Since the seawater flow speed varies along the riser length, the vortex shedding frequency corresponding to each element will also change continuously. Strictly speaking, the seawater flow speed at different points of each element is also different. However, when the number of the element is large enough, the variation of the seawater flow speed along the length of each element is very small. Therefore, the mean seawater flow speed corresponding to each element is used to calculate the vortex shedding frequency in the present study.

\section{Model and Numerical Solution Program Verification}

To verify the reliability of the improved model and numerical solution program established in the present study, comparisons with published experimental tests and numerical calculation results are carried out in this section. As we all know, the study of deep-water marine drilling risers VIV response is to provide the basis for the fatigue analysis and engineering design of the risers. The root-mean-square (RMS) displacement, peak frequency, and dominant mode are the main parameters of the riser fatigue analysis. The root-mean-square displacement can not only reflect the amplitude of the riser vibration but also reflect its vibration shape. The peak frequency and dominant mode mainly reflect the frequency and mode of the riser vibration, so this paper mainly analyzes these three parameters.

4.1. Long Flexible Riser. The experiment was conducted at Hanøytangen outside Bergen in Norway [37]. The main physical and geometric parameters of the riser model used in the experiment are given in Table 2. The riser model is divided equally into 300 elements, and this is enough to represent the maximum vibration mode that may occur for the riser VIV. The interval time in the calculation is $0.01 \mathrm{~s}$, and the total calculation time is $500 \mathrm{~s}$. These settings are sufficient to describe the main features of the riser VIV.

When the towing speed at riser upper end is $0.54 \mathrm{~m} / \mathrm{s}$, the experimental test and numerical calculation results of the inline and cross-flow VIV RMS displacements along the riser length are shown in Figure 3. The solid, dashed, and dotted lines represent the results of the experimental test, numerical calculation with an ideal added mass coefficient (the added mass coefficient is a constant value of 1.0), and numerical calculation with modified added mass coefficients, respectively. It can be seen from Figure 3 that the numerical calculation results with modified added mass coefficients reproduce the features of high order vibration in the in-line and cross-flow directions observed in the experimental test. The in-line and cross-flow VIV RMS displacements of the 
TABle 2: Main physical and geometric parameters of Lie and Kaasen riser model [37].

\begin{tabular}{lc}
\hline Parameters & Values \\
\hline Riser length $(\mathrm{m})$ & 90 \\
Outer diameter $(\mathrm{m})$ & 0.03 \\
Inner diameter $(\mathrm{m})$ & 0.026 \\
Bending stiffness $\left(\mathrm{N} \cdot \mathrm{m}^{2}\right)$ & 3640 \\
Riser density $\left(\mathrm{kg} / \mathrm{m}^{3}\right)$ & 3211 \\
Unit length mass $(\mathrm{kg} / \mathrm{m})$ & 2.27 \\
Mass ratio & 3.13 \\
Aspect ratio & 3000 \\
Top tension force $(\mathrm{N})$ & 3700 \\
\hline
\end{tabular}

riser obtained in the present study are larger than that of the experimental tests. The maximum relative errors of the riser VIV RMS displacement between the numerical calculation results in this paper and the experimental test results are $64.32 \%$ and $8.89 \%$, respectively. This may be explained from the following two aspects. On the one hand, it can be considered that it is caused by the inherent characteristics of the wake oscillator model itself. On the other hand, it can be considered that it is caused by the selection of the empirical parameters. In the experimental tests, the in-line and crossflow VIV dominant modes are 23rd and 11th, respectively. In the numerical calculations with modified added mass coefficients, the in-line and cross-flow VIV dominant modes are 20th and 12th, respectively. Meanwhile, according to the experimental test, the in-line and cross-flow VIV peak frequencies are $5.4 \mathrm{~Hz}$ and $2.1 \mathrm{~Hz}$, respectively. In the numerical calculations with modified added mass coefficients, the in-line and cross-flow VIV peak frequencies are $4.8 \mathrm{~Hz}$ and $2.4 \mathrm{~Hz}$, respectively. Peak frequency herein means the corresponding frequency to the highest spectral peak, taken from the spectra of VIV displacement at the midpoint of the riser model $[18,37]$. It can be seen that the riser VIV peak frequencies and dominant modes obtained in this paper are close to the experimental test results. Of course, there are some errors, especially in the prediction of the riser in-line VIV response, which is relatively large. However, in comparison to numerical calculations with the ideal added mass coefficient [18], it can be seen that the improved model established in this paper can not only accurately predict the cross-flow VIV response features but also more accurately predict the in-line VIV response features of long slender flexible risers in linearly sheared flow.

Figure 4(a) shows the average RMS displacements of the riser model under different towing speeds at the riser upper end. The solid symbols represent the experimental test results, and the hollow symbols represent the numerical calculation results based on the improved model established in this paper. It can be seen from Figure 4(a) that the numerical calculation results are larger than the experimental test results. In all the cases, the maximum relative errors in the in-line and cross-flow directions between the calculated results in this paper and the experimental test results are $42.95 \%$ and $12.48 \%$, respectively. However, in most cases, the numerical calculation results in this paper are close to the experimental test results. Besides, it can be seen that both the experimental test and numerical calculation results show that the change of the in-line and cross-flow average RMS displacements of the riser model is small with the variation of the towing speed. As we all know, the riser VIV displacements are affected by many factors. According to equation (8), when the towing speed increases, the vortex shedding frequency increases continuously. This will increase the riser VIV peak frequencies, which cause the riser VIV displacement to decrease. On the other hand, it can be known from equations (13) and (14) that when the towing speed increases, the external excitation forces acting on the riser increase continuously. This will make the VIV displacement of the riser tend to increase. Under the combined effect of these two aspects, the variations of the riser VIV displacements are irregular as the towing speed changes.

Figure 4(b) shows the peak frequencies of the riser model under different towing speeds at the riser upper end. It can be seen from Figure 4(b) that both the experimental test results and the numerical calculation results show that the in-line and cross-flow peak frequencies increase gradually with the increase of the towing speed. This is because, with the increase of the towing speed, the vortex shedding frequency, that is to say, the external excitation force frequency, increases continuously, which makes the riser VIV peak frequencies increase gradually. It can be found from Figure 4(b) that both the experimental test results and the numerical calculation results show that the in-line VIV peak frequency is about two times the cross-flow VIV peak frequency. It can be known from equations (13)-(16) that this is because the frequency of the external excitation force acting on the riser in the in-line direction is about two times the frequency of the external excitation force acting on the riser in the cross-flow direction. At the same time, it can be seen from Figure 4(b) that, except for a few cases, the riser VIV peak frequencies obtained in this paper are close to the experimental test results. In Figure 4(b), the lower dashed line corresponds to the Strouhal frequency $\left(f_{s}=S_{t} u / D\right)$ based on the towing speed, and the upper solid line corresponds to two times the Strouhal frequency. It can be seen from Figure 4(b) that the cross-flow VIV frequency of the riser is lower than the Strouhal frequency, which is the same as the trend obtained in the experimental test. According to equations (8) and (9), under sheared flow, the vortex shedding frequency decreases gradually along with the water depth. This is different from the constant vortex shedding frequency in uniform flow. Therefore, the cross-flow peak frequency of the riser is lower than the vortex shedding frequency corresponding to the maximum towing speed.

4.2. Relatively Long Flexible Riser. The experiment was conducted at Marintek's Ocean Basin in Trondheim [38]. The main physical and geometric parameters of the riser model used in the experiment are given in Table 3 . The riser model is divided equally into 190 elements. The interval time in the calculation is $0.01 \mathrm{~s}$, and the total calculation time is $500 \mathrm{~s}$.

Figure 5(a) shows the maximum RMS displacements of the riser model under different current velocities. The 


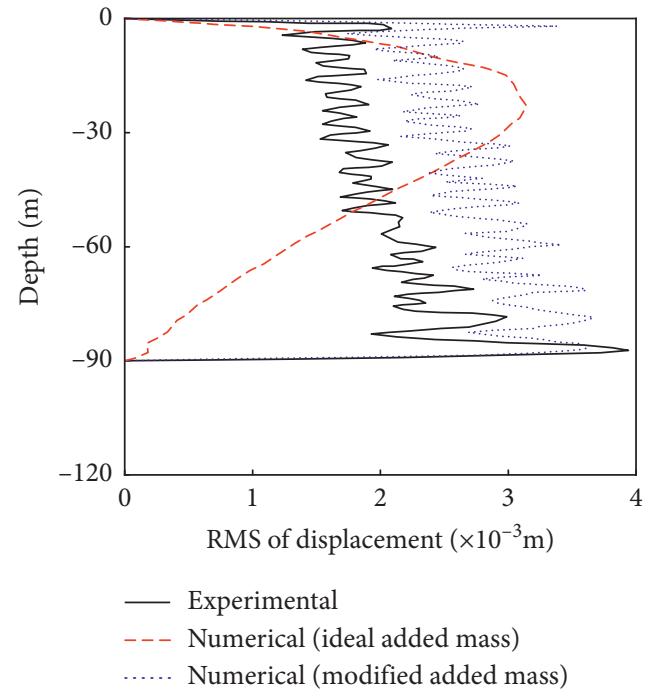

(a)

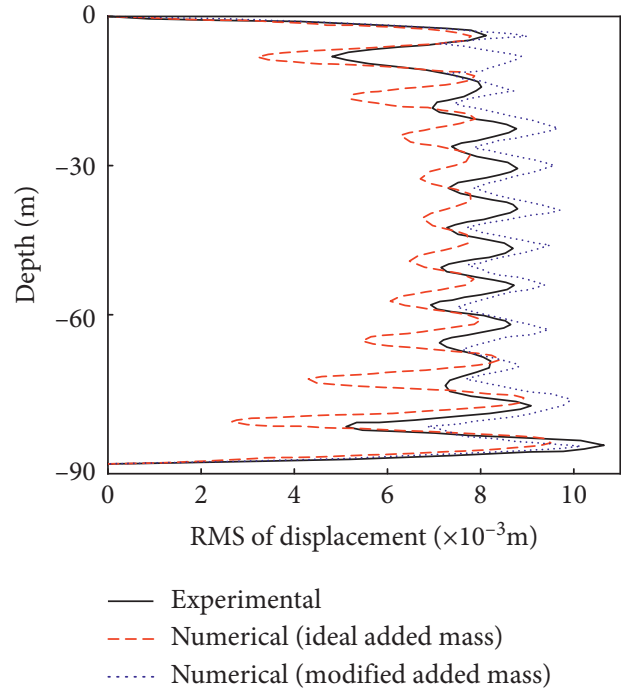

(b)

FIGURE 3: Comparison of the in-line and cross-flow RMS displacements of the riser model when the towing speed at the riser upper end is $0.54 \mathrm{~m} / \mathrm{s}[18,37]$. (a) In-line direction. (b) Cross-flow direction.

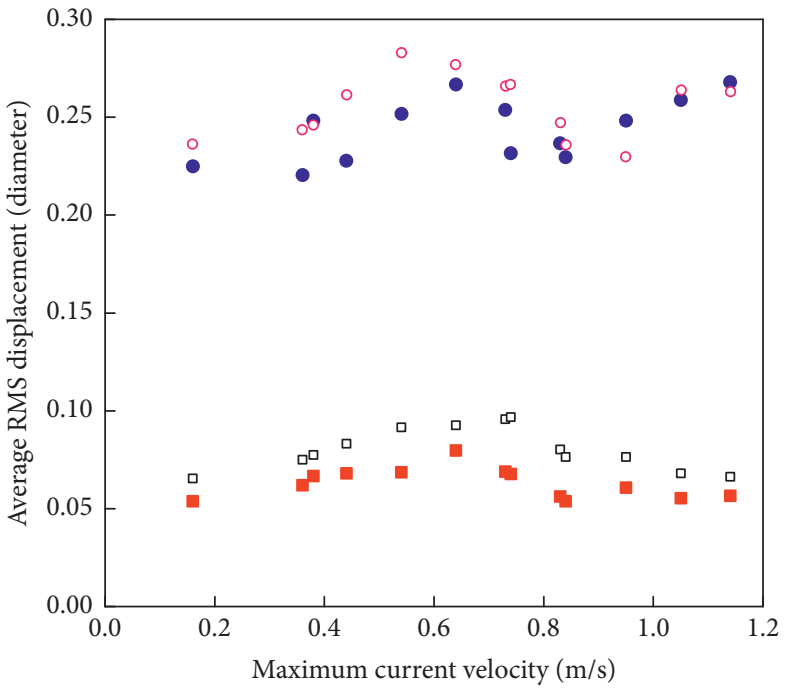

IL experimental test

- CF experimental test $\square$ IL numerical simulation

○ CF numerical simulation

(a)

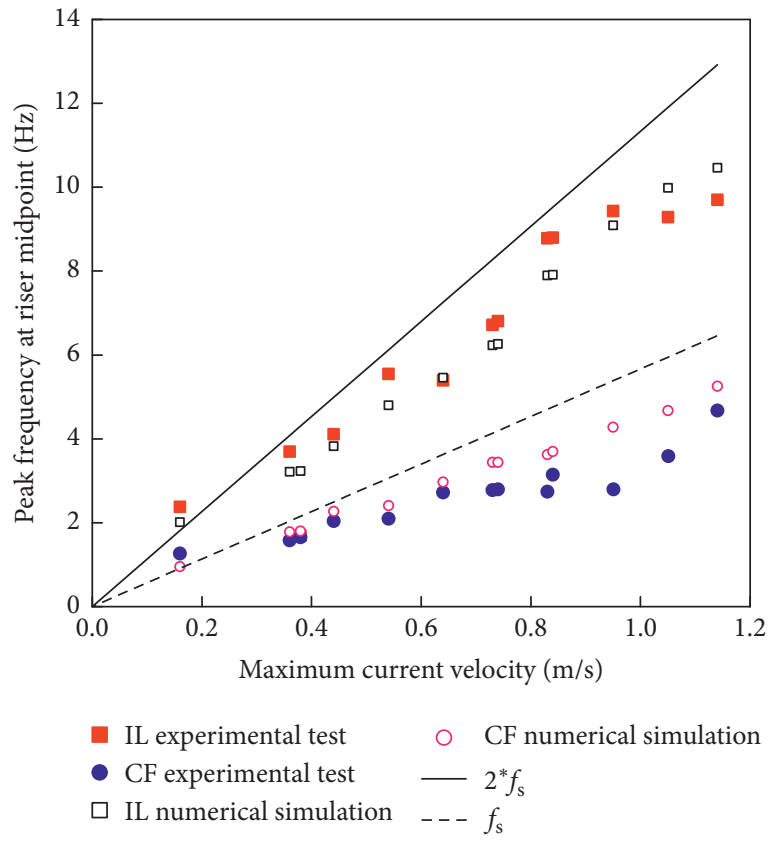

(b)

FIgUre 4: (a) Average RMS displacement and (b) peak frequency of the riser model under different towing speeds [37].

TABle 3: Main physical and geometric parameters of Trim et al.'s riser model [38].

\begin{tabular}{lc}
\hline Parameters & Values \\
\hline Riser length $(\mathrm{m})$ & 38 \\
Outer diameter $(\mathrm{m})$ & 0.027 \\
Inner diameter $(\mathrm{m})$ & 0.021 \\
Young's modulus $(\mathrm{Pa})$ & $3.62 \times 10^{10}$ \\
Mass ratio & 3.13 \\
Aspect ratio & 1407 \\
Top tension force $(\mathrm{N})$ & 5000 \\
\hline
\end{tabular}

symbol definitions are the same as in Figure 4. It can be seen from Figure 5(a) that both the experimental test and numerical calculation results show that the change of the riser in-line and cross-flow maximum RMS displacements is irregular with the variation of the current velocity. Compared with the experimental test results, the riser in-line and cross-flow maximum RMS displacements obtained in this paper vary relatively little with the change of the current velocity. The numerical calculation results are a little smaller than the experimental test results. In all cases, the maximum 


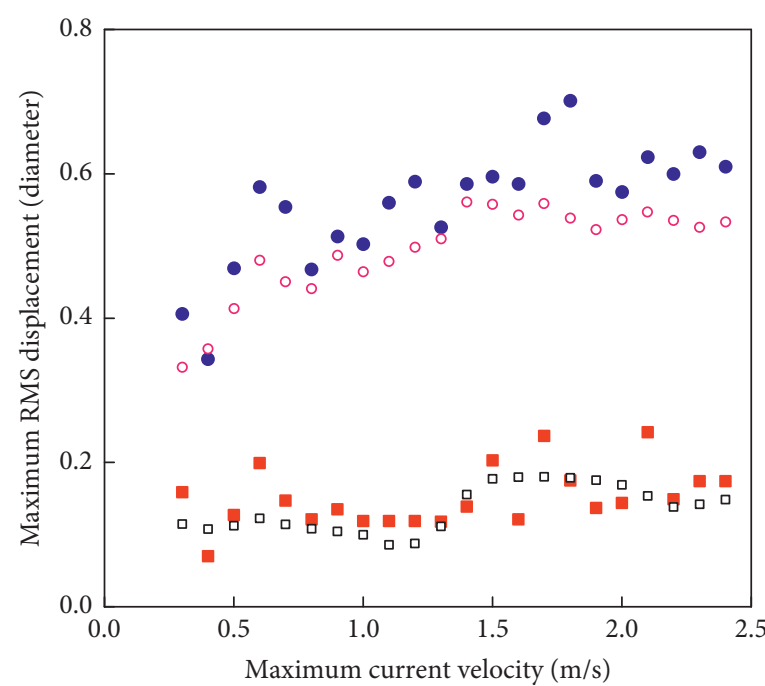

- IL experimental test - CF experimental test $\square$ IL numerical simulation

○ CF numerical simulation

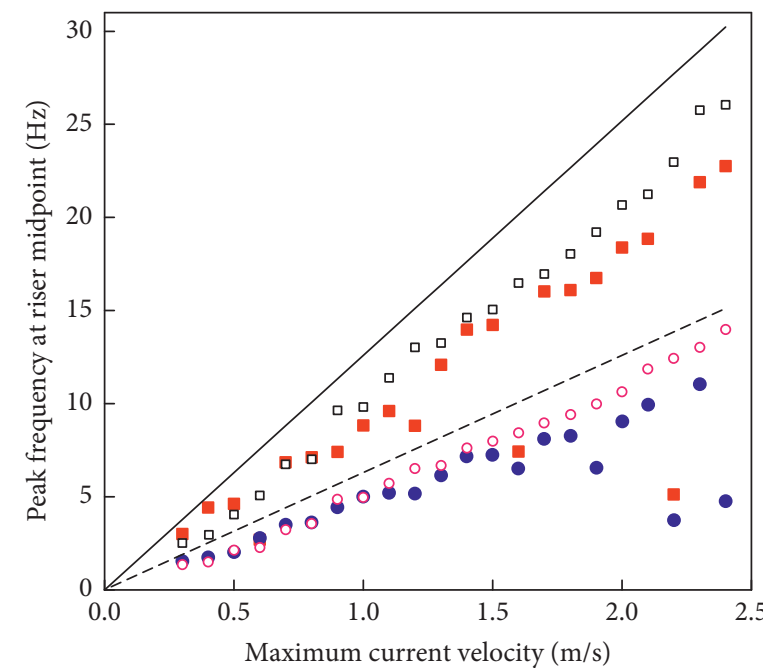

IL experimental test

- CF experimental test

○ CF numerical simulation

IL numerical simulation

$2 * f_{s}$

(a)

(b)

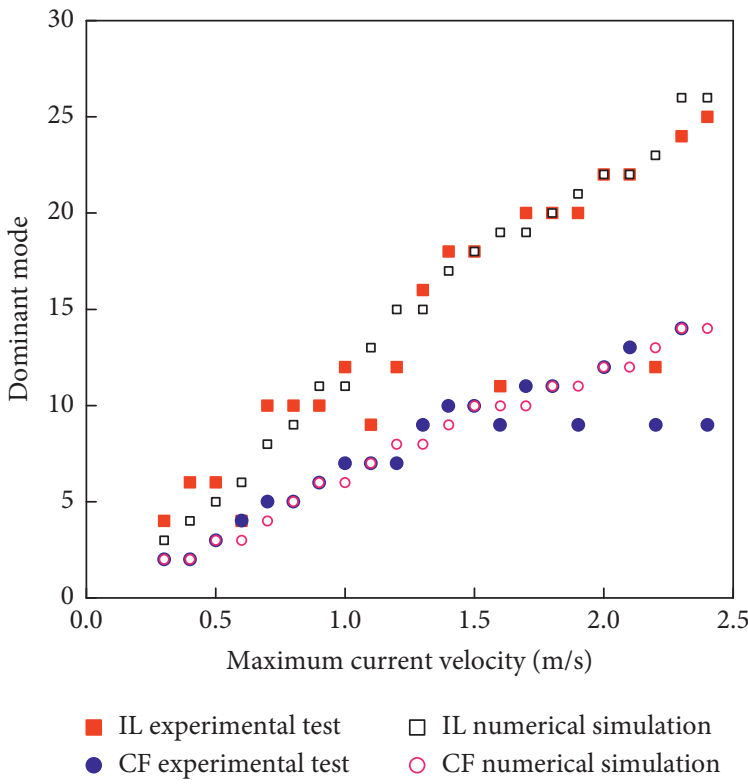

(c)

Figure 5: (a) Maximum RMS displacement, (b) peak frequency, and (c) dominant mode of the riser model under different current velocities [38].

relative errors in the in-line and cross-flow directions between the calculated results in this paper and the experimental test results are $53.71 \%$ and $23.10 \%$, respectively. However, except for a few cases, the numerical calculation results in this paper are close to the experimental test results in most cases. Figures 5(b) and 5(c) show the peak frequencies and dominant modes of the riser model under different current velocities. It can be seen from Figures 5(b) and 5(c) that the numerical calculation results show that the in-line and cross-flow peak frequencies and dominant modes increase gradually with the increase of the current velocity. Except for a few cases, the experimental test results also show that the in-line and cross-flow peak frequencies and dominant modes increase gradually with the increase of the current velocity. Overall, the in-line and cross-flow peak frequencies and dominant modes obtained in this paper are close to the experimental test results.

From the comparisons of Figures 3-5, it can be seen that the relative errors between the numerical calculation results obtained in this paper and the experimental tests in the inline direction are a little large, but the relative errors in the cross-flow direction are relatively small. On the whole, 
except for a few cases, the numerical calculation results based on the improved model established in this paper are close to the experimental test results to some extent. Given the inherent limitations of the semiempirical models based on wake oscillator models, the improved coupled model and numerical solution program established in this paper can be used to predict the in-line and cross-flow VIV response of marine drilling risers in the actual deep-water oil/gas engineering.

\section{Case Study and Results Discussion}

In this section, the VIV of a real-size marine drilling riser, usually used in the actual deep-water oil/gas drilling industry in the South China Sea, is analyzed. The main physical and geometric parameters of the riser are given in Table 4 . According to the element precision analysis, the riser is divided equally into 400 elements in the calculation. The interval time in the calculation is $0.01 \mathrm{~s}$, and the total calculation time is $1000 \mathrm{~s}$.

Figure 6 shows the in-line and cross-flow VIV RMS displacements along the riser length. The values of the top tension force coefficient, surface seawater flow speed, platform heave amplitude, and frequency are $1.4,0.8 \mathrm{~m} / \mathrm{s}, 1.0 \mathrm{~m}$, and $0.8 \mathrm{rad} / \mathrm{s}$, respectively. The solid line indicated by the VIV legend in Figure 6 represents the riser VIV when the time-dependent axial tension force component is not considered. The dotted line indicated by the PVIV legend in Figure 6 represents the riser VIV when the time-dependent axial tension force component is taken into account. It can be seen from Figure 6 that the in-line VIV and PVIV maximum RMS displacements are 0.158 and 0.195 of the riser outer diameter, respectively, and the cross-flow VIV and PVIV maximum RMS displacements are 0.508 and 0.596 of the riser outer diameter, respectively. It can be found that the cross-flow RMS displacement is about three times the in-line RMS displacement. The cross-flow vibration displacement dominates the overall displacement, which is consistent with the experimental tests and other numerical studies [12-20,37, 38]. It can be noted from Figure 6 that the platform heave motion increases the in-line and cross-flow VIV displacements. According to equations (1)-(3), when the axial tension force of the riser changes dynamically, the riser lateral bending stiffness changes continuously. Under the same external force, this will increase the vibration response of the riser. Accordingly, the riser PVIV RMS displacements are larger than the VIV RMS displacements. Besides, it can be seen from Figure 6 that the in-line VIV and PVIV dominant modes are 20th and 19th, respectively, and the cross-flow VIV and PVIV dominant modes are all 11th. It is clear that the platform heave motion changes the vibration modes of the middle and upper sections of the riser. This is because the vortex shedding frequency of the middle and upper sections of the riser is relatively large, and the VIV response of the riser is more sensitive to the changes in axial tension force. Therefore, when the axial tension force changes dynamically, the vibration modes of the upper and middle sections of the riser
TABLE 4: Main physical and geometric parameters of the marine drilling riser.

\begin{tabular}{lc}
\hline Parameters & Values \\
\hline Water depth (riser length), $H(\mathrm{~m})$ & 2000 \\
Outer diameter, $D(\mathrm{~m})$ & 0.5334 \\
Inner diameter, $d(\mathrm{~m})$ & 0.4826 \\
Elastic modulus, $E(\mathrm{~Pa})$ & $2.1 \times 10^{11}$ \\
Riser density, $\rho_{\mathrm{r}}\left(\mathrm{kg} / \mathrm{m}^{3}\right)$ & 7850 \\
Internal fluid density, $\rho_{\mathrm{f}}\left(\mathrm{kg} / \mathrm{m}^{3}\right)$ & 1200 \\
Seawater density, $\rho_{\mathrm{w}}\left(\mathrm{kg} / \mathrm{m}^{3}\right)$ & 1025 \\
Mass ratio & 2.35 \\
Aspect ratio & 3750 \\
Top tension force coefficient, $\left.f_{\text {top }} / \mathrm{s}\right)$ & $1.2 \sim 1.6$ \\
Surface seawater flow speed, $u_{\mathrm{s}}(\mathrm{m} / \mathrm{s})$ & $0.5 \sim 1.0$ \\
Bottom seawater flow speed, $u_{\mathrm{b}}(\mathrm{m} / \mathrm{s})$ & 0.1 \\
Platform heave amplitude, $\widetilde{A}(\mathrm{~m})$ & $0 \sim 2.0$ \\
Platform heave frequency, $\widetilde{\Omega}(\mathrm{rad} / \mathrm{s})$ & $0 \sim 2.0$ \\
\hline
\end{tabular}

change greatly. It is clear that the platform heave motion has a significant impact on the riser vibration response.

Figure 7 shows the in-line and cross-flow VIV displacement spectrums at the midpoint of the riser. The displacement spectrum herein refers to the spectrum curve obtained by the Fourier transform of the riser VIV displacement. It can be noted from Figure 7 that the in-line VIV and PVIV peak frequencies are $0.416 \mathrm{~Hz}$ and $0.412 \mathrm{~Hz}$, respectively, and the cross-flow VIV and PVIV peak frequencies are $0.23 \mathrm{~Hz}$ and $0.226 \mathrm{~Hz}$, respectively. The corresponding Strouhal frequency is $0.255 \mathrm{~Hz}$ when the surface seawater flow speed is $0.8 \mathrm{~m} / \mathrm{s}$. The cross-flow VIV frequency of the riser is lower than the Strouhal frequency, which is the same as the trend obtained in the experimental test and other numerical studies $[18,37,38]$. It can also be seen from Figure 7 that whether or not the platform heave motion is considered, the riser VIV are all showing multifrequency vibration in both the in-line and cross-flow directions. This is also the same as the trend obtained in the experimental test and other numerical studies $[12-20,37,38]$. Moreover, it can be found from Figure 7(a) that the displacement spectrum shows a peak value at the point of the platform heave frequency. Meanwhile, it can be seen from Figure 7(b) that the displacement spectrum shows peak values at the points of difference and sum frequencies between the peak frequency of the riser and the platform heave frequency. This is determined by vortex shedding frequency and the axial tension force variation frequency. It is clear that the platform heave motion not only changes the magnitudes of the in-line and cross-flow peak frequencies but also changes the components of the in-line and crossflow VIV frequencies.

5.1. Influence of Seawater Flow Speed. The variation of the seawater flow speed causes a change in the vortex shedding frequency, which in turn changes the VIV response features of the riser. To reasonably design the riser, it is necessary to accurately grasp the riser VIV response features under different situations. According to the environmental condition in the South China Sea, the surface seawater flow 


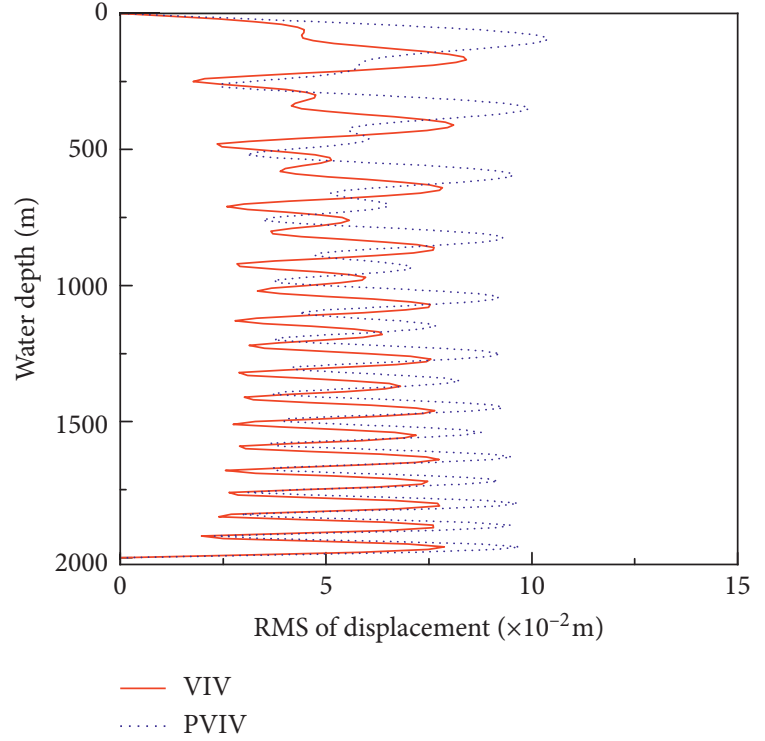

(a)

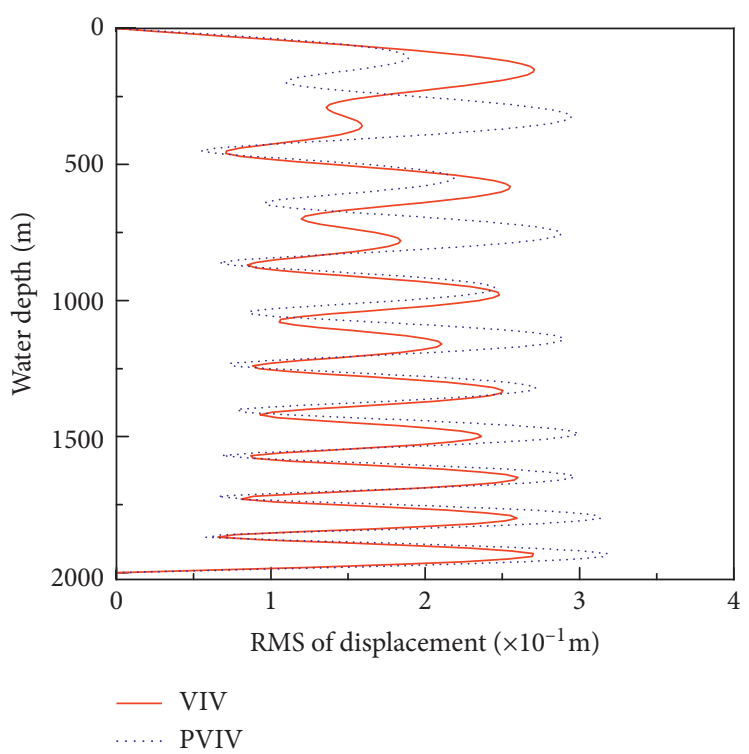

(b)

Figure 6: RMS displacement of the marine drilling riser. (a) In-line direction. (b) Cross-flow direction.

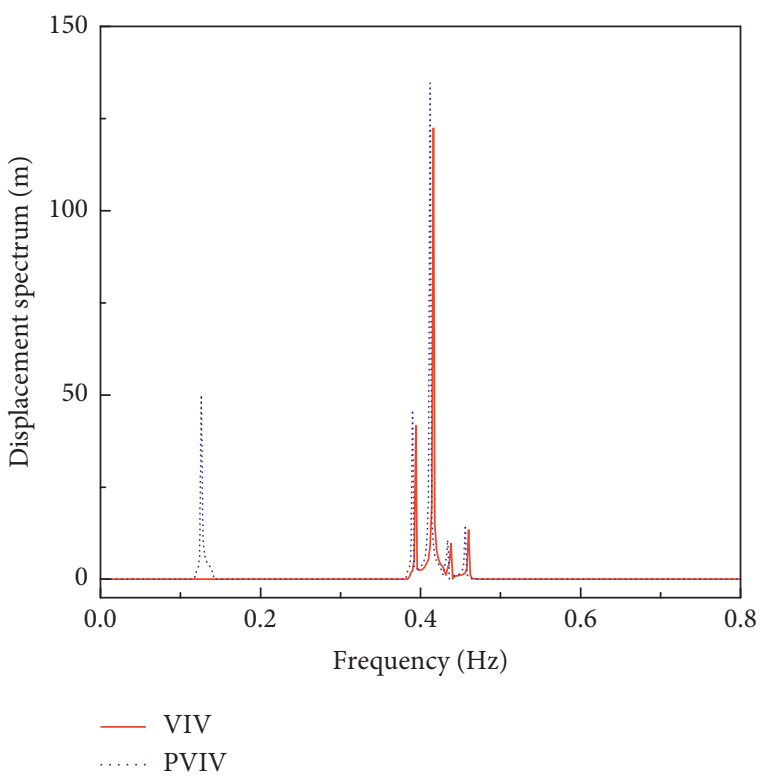

(a)

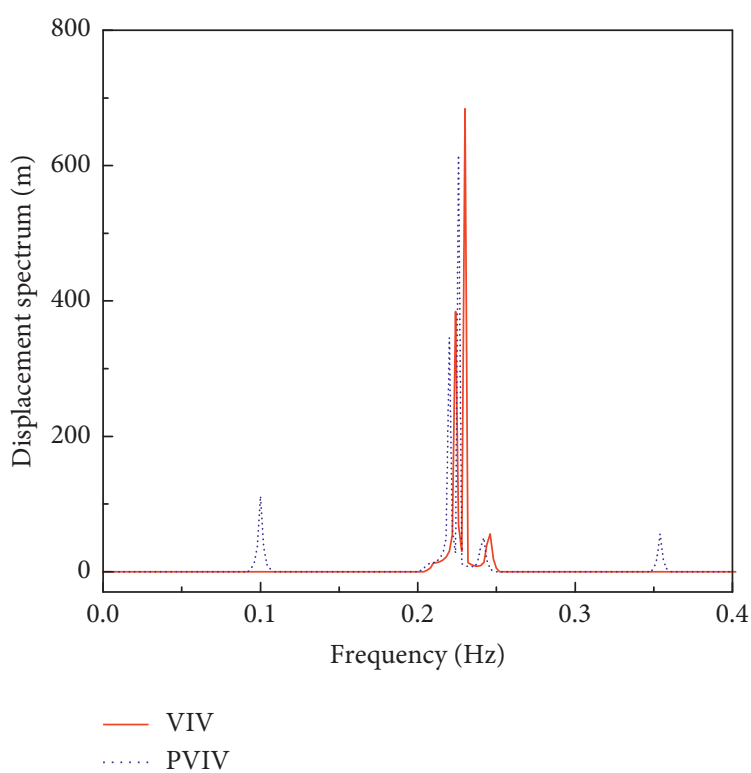

(b)

FIgURE 7: Displacement spectrum at the midpoint of the marine drilling riser. (a) In-line direction. (b) Cross-flow direction.

speed usually ranges from 0.5 to $1.0 \mathrm{~m} / \mathrm{s}$. In this section, the influence of the seawater flow speed on the riser VIV response is analyzed. The top tension force coefficient, platform heave amplitude, and frequency are $1.4,1.0 \mathrm{~m}$, and $0.8 \mathrm{rad} / \mathrm{s}$, respectively.

The in-line and cross-flow average RMS displacements of the riser at different surface seawater flow speeds are shown in Figure 8(a). It can be seen from Figure 8(a) that the variations of the in-line and cross-flow average RMS displacements are irregular with the increase of the surface seawater flow speed. The in-line average RMS displacement varies between 0.069 and 0.117 of the riser outer diameter, and the cross-flow average RMS displacement varies between 0.236 and 0.35 of the riser outer diameter. Moreover, it can be noted from Figure 8(a) that the surface seawater flow speeds corresponding to the maximum in-line and cross-flow average RMS displacements are different. It can be known from this that when the seawater flow speed changes, the variation rules of the riser in-line and cross-flow are related to factors such as the vortex shedding frequency, the seawater flow speed, and the axial tension force. According to equations (8), (13), and (14), when the seawater 


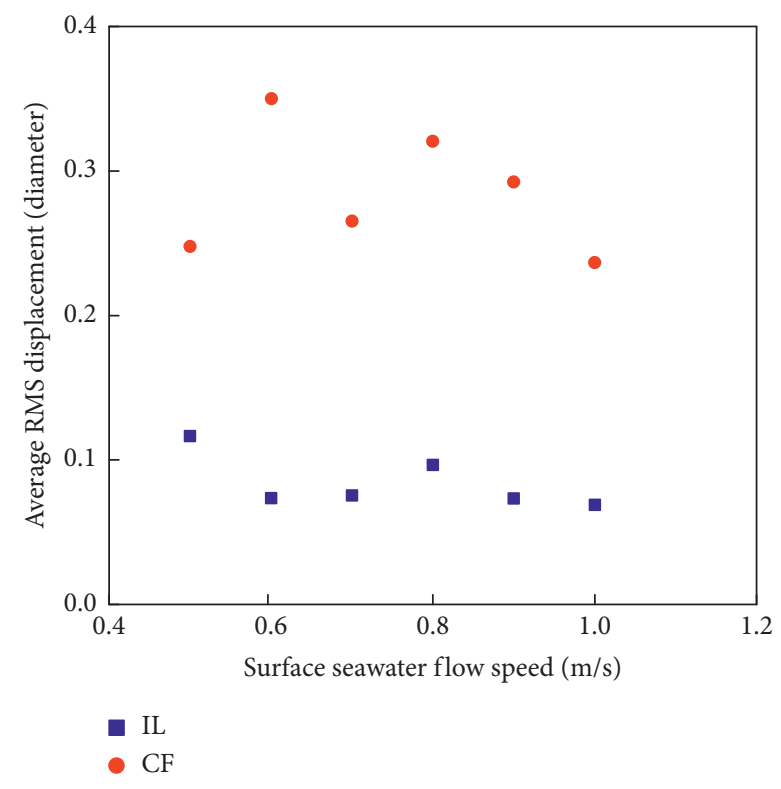

(a)

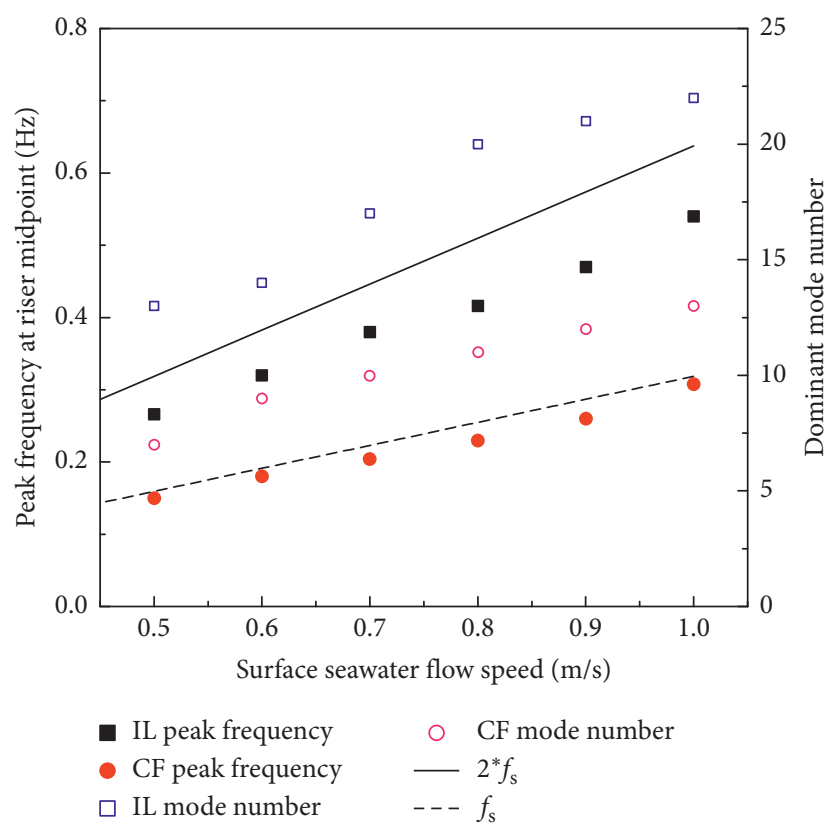

(b)

Figure 8: (a) Average RMS displacement and (b) peak frequency and dominant mode versus surface seawater flow speed.

flow speed changes, both the vortex shedding frequency and the external excitation force change. All of these will affect the riser VIV displacement. Therefore, when the seawater flow speed changes, the VIV displacement of the riser changes irregularly. At the same time, according to equations (11) and (12), it can be known that the frequency of the external excitation force in the in-line direction and the cross-flow direction is not the same. Thus, the change of the seawater flow speed has different effects on the riser VIV displacement in the in-line and cross-flow directions. Figure 8(b) shows how the in-line and cross-flow peak frequencies and dominant modes of the riser vary with the surface seawater flow speed. According to equation (8), the vortex shedding frequency will increase as the seawater flow speed increases. That is to say, the frequency of external excitation forces on the riser continues to increase as the seawater flow speed increases. Therefore, it can be seen from Figure 8(b) that the in-line and cross-flow peak frequencies and dominant modes are all increasing continuously with the increase of the seawater flow speed.

5.2. Influence of Top Tension Force. The top tension force plays a significant role in the offshore oil/gas drilling industry. The variation of the top tension force will inevitably change the natural vibration features and geometric stiffness of the riser, which results in a change in the riser VIV response. According to the engineering practice, the top tension force coefficient is usually in the range of 1.2 to 1.6. In this section, the influence of the top tension force on the riser VIV response is analyzed. The surface seawater flow speed, platform heave amplitude, and frequency are $0.8 \mathrm{~m} / \mathrm{s}$, $1.0 \mathrm{~m}$, and $0.8 \mathrm{rad} / \mathrm{s}$, respectively.
The in-line and cross-flow average RMS displacements of the riser at different top tension force coefficients are shown in Figure 9(a). It can be seen from Figure 9(a) that the in-line average RMS displacement shows an increasing trend on the whole with the increase of the top tension force, but the variation of the cross-flow average RMS displacement is irregular with the increase of the top tension force. The inline average RMS displacement varies from 0.064 to 0.136 of the riser outer diameter, and the cross-flow average RMS displacement varies between 0.234 and 0.349 of the riser outer diameter. Moreover, it can be found from Figure 9(a) that the top tension force coefficients corresponding to the maximum in-line and cross-flow average RMS displacements are different. It can be known from this that when the seawater flow speed changes, the variation rules of the riser in-line and cross-flow average RMS displacements are not the same. As mentioned above, the riser VIV displacement is related to the influence of several factors. According to equations (1)-(3), when the riser axial tension force changes, the riser lateral bending stiffness, natural vibration frequency, and VIV peak frequency all change. All of these will affect the riser VIV displacement. Thus, the riser VIV displacements change irregularly with the changes of the top tension force coefficient. Figure 9(b) shows how the in-line and cross-flow VIV peak frequencies and dominant modes of the riser vary with the top tension force coefficient. It can be seen from Figure 9(b) that the in-line and cross-flow peak frequencies and dominant modes are all decreasing gradually as the top tension force coefficient increases. As we know, the natural vibration frequency of the riser decreases continuously with the increase of the top tension force coefficient. At the same time, the frequency of external excitation forces on the riser remains unchanged at the same 


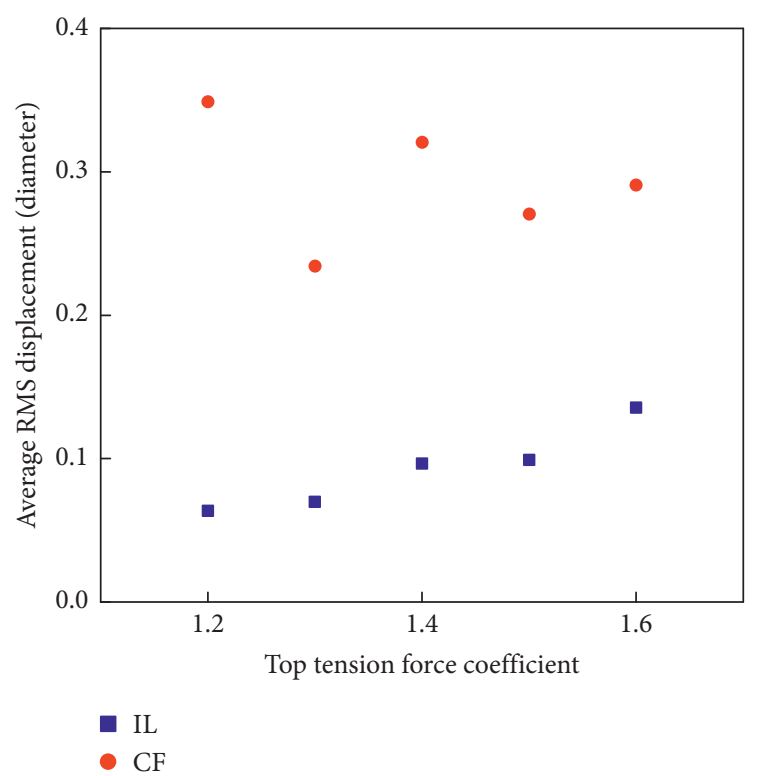

(a)

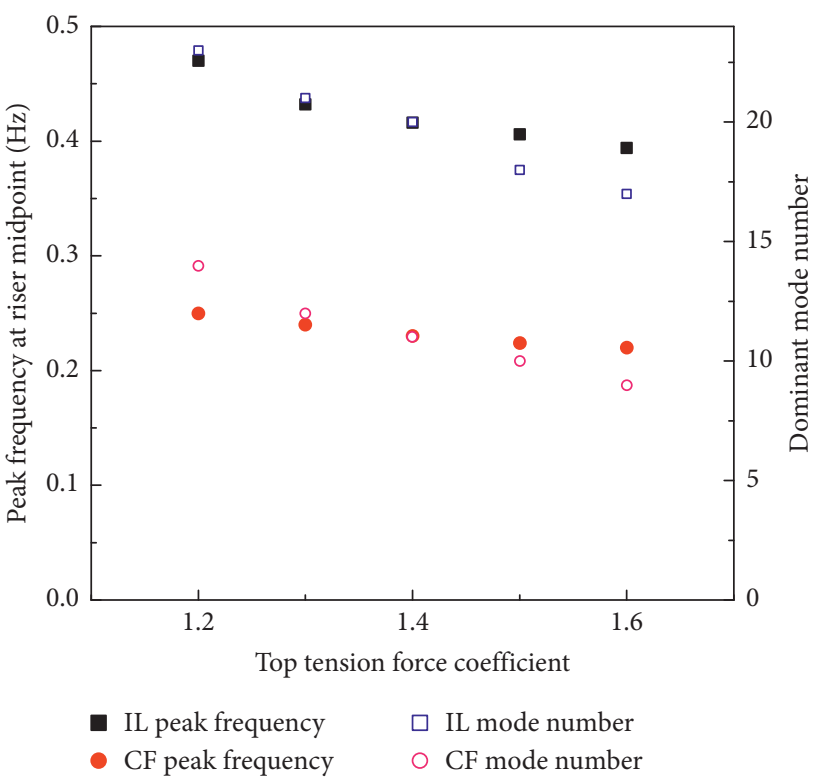

(b)

Figure 9: (a) Average RMS displacement and (b) peak frequency and dominant mode versus top tension force coefficient.

seawater flow speed. Therefore, when the top tension force coefficient increases, the riser VIV peak frequencies and dominant mode numbers decrease continuously.

5.3. Influence of Platform Heave Amplitude. According to equation (3), the change of the platform heave amplitude will change the variation range of the riser axial tension force, which will affect the riser VIV. According to the engineering practice, the platform heave amplitude usually ranges from 0 to $2.0 \mathrm{~m}$. In this section, the influence of the platform heave amplitude on the riser VIV is analyzed. The top tension force coefficient, surface seawater flow speed, and platform heave frequency are $1.6,0.8 \mathrm{~m} / \mathrm{s}$, and $0.8 \mathrm{rad} / \mathrm{s}$, respectively.

The riser in-line and cross-flow maximum RMS displacements at different platform heave amplitudes are shown in Figure 10(a). It can be seen from Figure 10(a) that the in-line and cross-flow maximum RMS displacements are all increasing gradually with the increase of the platform heave amplitude. The in-line maximum RMS displacement varies from 0.185 to 0.213 of the riser outer diameter, and the cross-flow maximum RMS displacement varies from 0.582 to 0.676 of the riser outer diameter. According to equation (3), the larger the platform heave amplitude is, the larger the change range of the riser axial tension force is, which results in the more severe vibration of the riser. As a result, the average RMS displacements of the riser will increase continuously. Moreover, it can also be noted from Figure 10(a) that the variation of the platform heave amplitude has a greater influence on the maximum RMS displacement in the cross-flow direction than in the in-line direction. This is because the cross-flow external excitation force is much greater than that of the in-line external excitation force. Thus, when the top tension force changes, the change degree of the riser VIV displacement in the cross-flow direction is greater than that in the in-line direction. Figure 10(b) shows how the in-line and cross-flow peak frequencies and dominant modes of the riser vary with the platform heave amplitude. It can be found from Figure 10(b) that the in-line and cross-flow peak frequencies are all decreasing gradually with the increase of the platform heave amplitude. Meanwhile, it can be seen from Figure 10(b) that the in-line and cross-flow dominant modes are all showing a decreasing trend on the whole with the increase of the platform heave amplitude. However, in some conditions, the in-line and cross-flow dominant modes do not change when the platform heave amplitude changes little. As mentioned above, when the platform heave amplitude increases, the change range of the riser axial tension force increases. This will decrease the riser natural vibration frequency. Thus, when the external excitation force remains unchanged, the riser VIV peak frequencies and dominant modes are all decreasing gradually with the increase of the platform heave amplitude.

5.4. Influence of Platform Heave Frequency. According to equation (3), the change of the platform heave frequency will change the variation frequency of the riser axial tension force, which will affect the riser VIV. According to the engineering practice, the platform heave frequency usually ranges from 0 to $2.0 \mathrm{rad} / \mathrm{s}$. In this section, the influence of the platform heave frequency on the riser VIV is analyzed. The top tension force coefficient, surface seawater flow speed, and platform heave amplitude are $1.6,0.8 \mathrm{~m} / \mathrm{s}$, and $1.0 \mathrm{~m}$, respectively.

The in-line and cross-flow maximum RMS displacements of the riser at different platform heave frequencies are shown in Figure 11(a). It can be seen from Figure 11(a) that 


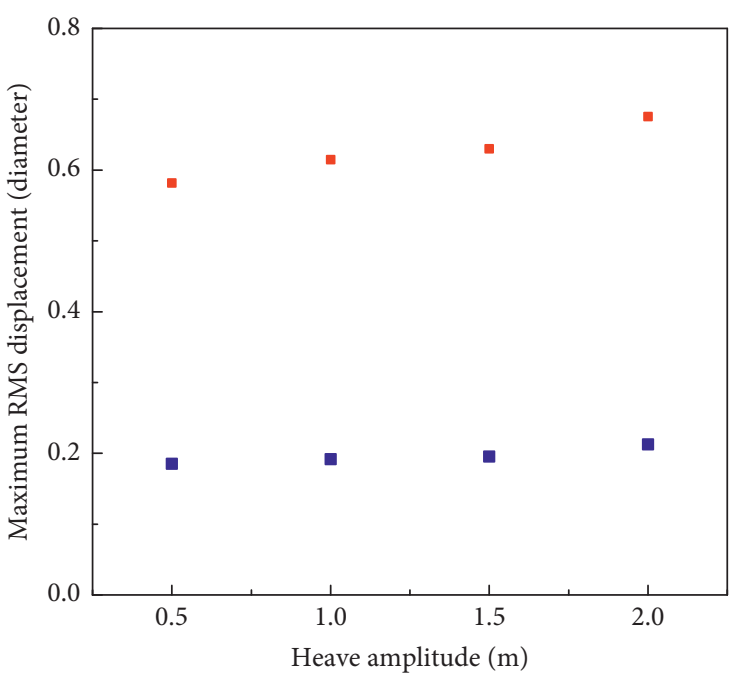

- IL

- $\mathrm{CF}$

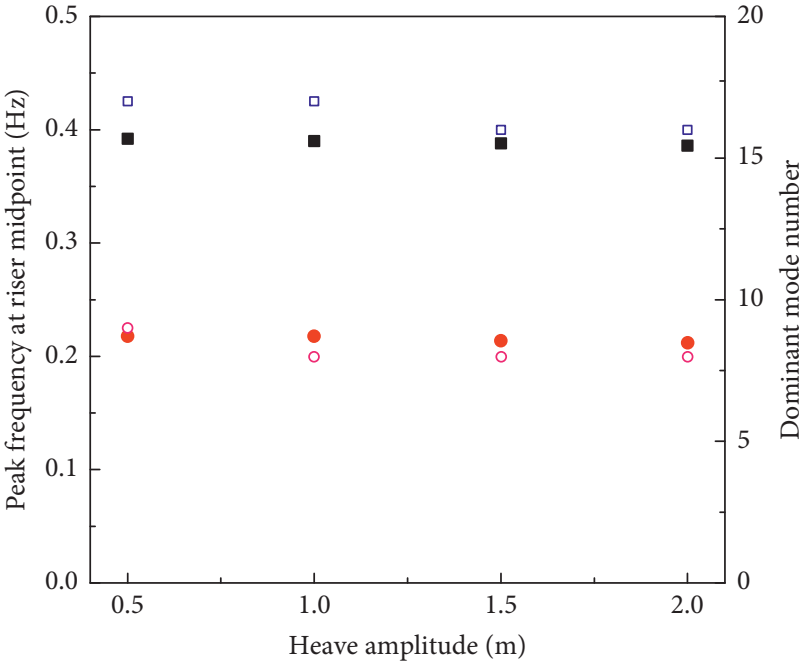

IL peak frequency $\quad \square$ IL mode number

- CF peak frequency $\quad \mathrm{CF}$ mode number

(b)

Figure 10: (a) Maximum RMS displacement and (b) peak frequency and dominant mode versus platform heave amplitude.

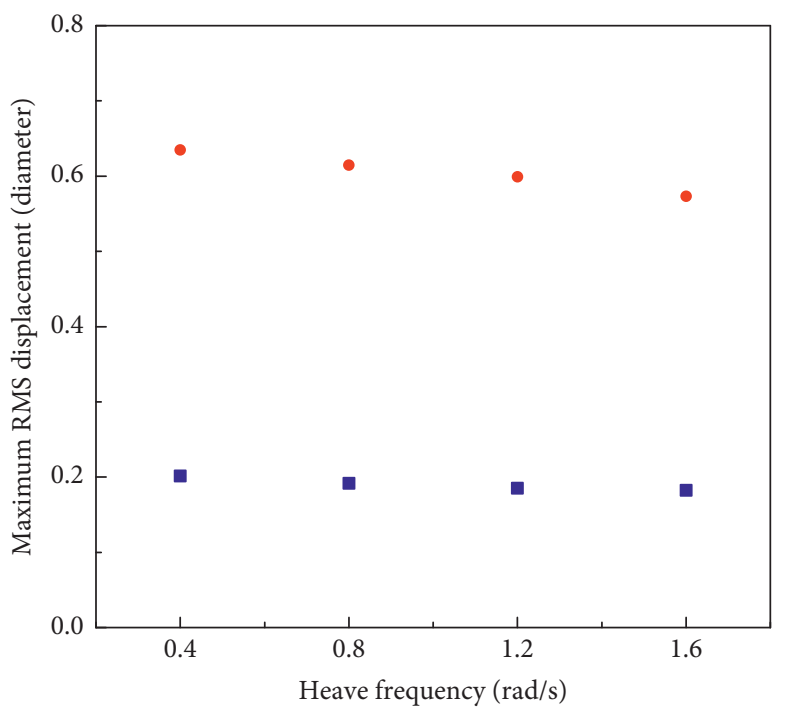

IL

CF

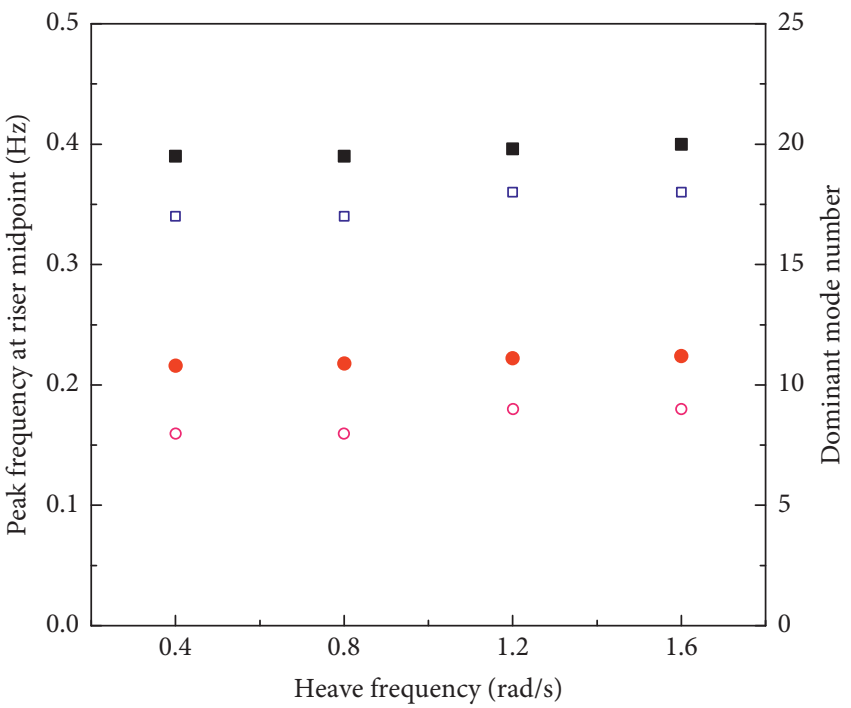

IL peak frequency $\quad \square$ IL mode number

- CF peak frequency $\quad \mathrm{CF}$ mode number

(b)

Figure 11: (a) Maximum RMS displacement and (b) peak frequency and dominant mode versus platform heave frequency.

the riser in-line and cross-flow maximum RMS displacements are all decreasing gradually with the increase of the platform heave frequency. The in-line maximum RMS displacement varies from 0.201 to 0.183 of the riser outer diameter, and the cross-flow maximum RMS displacement varies from 0.635 to 0.573 of the riser outer diameter. Moreover, it can be noted from Figure 11(a) that the variation of the platform heave frequency has a greater influence on the riser maximum RMS displacement in the crossflow direction than in the in-line direction. As mentioned above, the riser VIV displacements are affected by several factors. As the platform heave frequency increases, the change frequency of the riser lateral bending stiffness increases. When the external excitation forces remain unchanged, the VIV response of the riser decreases. Therefore, the riser VIV displacement decreases gradually with the increase of the platform heave frequency. Figure 11(b) shows how the in-line and cross-flow peak frequencies and dominant modes of the riser vary with the platform heave frequency. It can be found from Figure 11(b) that the in-line 
and cross-flow peak frequencies are all increasing gradually with the increase of the platform heave frequency. Meanwhile, it can be found from Figure 11(b) that the in-line and crossflow dominant modes are all showing an increasing trend on the whole with the increase of the platform heave frequency. However, in some conditions, the in-line and cross-flow dominant mode numbers of the riser do not change when the platform heave frequency changes little. As mentioned above, when the platform heave frequency increases, the change frequency of the riser axial tension force increases. This will increase the riser natural vibration frequency. Thus, when the external excitation forces remain unchanged, the riser VIV peak frequencies and dominant modes are all increasing gradually with the increase of the platform heave frequency.

\section{Conclusions}

In this paper, an improved three-dimensional time-domain coupled model is established to predict the in-line and crossflow vortex-induced vibration of deep-water marine drilling risers in linearly sheared flows in consideration of the changing added mass coefficients. The coupled model is based on van der Pol wake oscillator models to simulate the hydrodynamic features in the wake region of risers. The inline and cross-flow added mass coefficients developed in the previously published paper are adopted in the present study. Comparisons between the numerical calculation and the published experimental test are carried out in this paper. The VIV response of a real-size marine drilling riser, usually used in the practical deep-water oil/gas drilling industry in the South China Sea, is analyzed. The influence of the top tension force and seawater flow speed, as well as platform heave amplitude and frequency, on the riser VIV response is also discussed. The main conclusions drawn are as follows:

(1) Compared with the existing prediction models based on the ideal added mass coefficient (the added mass coefficient is a constant value of 1.0), the predicted results of the improved model are more consistent with the experimental test results. Overall, the improved coupled model can accurately predict some main features of the in-line and cross-flow VIV response of deep-water marine drilling risers in linearly sheared flows to some extent.

(2) The platform heave motion increases the riser VIV displacements and changes the magnitudes of peak frequencies as well as the components of frequencies. In the in-line direction, the displacement spectrum shows peak value at the point of the platform heave frequency. In the cross-flow direction, the displacement spectrum shows peak values at the points of difference and sum frequencies between the peak frequency of the riser and the platform heave frequency. The platform heave motion has a significant influence on the vibration modes of the middle and upper sections of the riser.

(3) With the change of the seawater flow speed or top tension force, the variations of the in-line and crossflow displacements are irregular. The seawater flow speeds or top tension force coefficients corresponding to the maximum in-line and cross-flow displacements are different. The in-line and cross-flow peak frequencies and dominant modes increase gradually with the increase of the seawater flow speed. With the increase of the top tension force, the peak frequencies and dominant modes decrease gradually.

(4) With the increase of the platform heave amplitude, the riser in-line and cross-flow VIV displacements increase gradually. The change of the platform heave amplitude has a greater influence on the displacement in the cross-flow direction than in the in-line direction. The in-line and cross-flow peak frequencies decrease gradually with the increase of the platform heave amplitude. The in-line and cross-flow dominant modes are showing a decreasing trend on the whole with the increase of the platform heave amplitude. However, in some conditions, the in-line and cross-flow dominant modes do not change when the platform heave amplitude changes.

(5) With the increase of the platform heave frequency, the riser in-line and cross-flow VIV displacements decrease gradually. The influences of the variation of the platform heave frequency on the in-line and cross-flow displacements are different. The in-line and cross-flow peak frequencies increase gradually with the increase of the platform heave frequency. The in-line and cross-flow dominant modes are showing an increasing trend on the whole with the increase of the platform heave frequency. However, in some conditions, the in-line and cross-flow dominant modes do not change when the platform heave frequency changes.

Accurate prediction of coupled in-line and cross-flow VIV response of deep-water marine drilling risers with a large aspect ratio in sheared flows is a challenging problem. At present, all semiempirical models have certain limitations in predicting the coupled in-line and cross-flow VIV response of marine drilling risers. The improved coupled model established in this paper also has some shortcomings. In the future, we will revise the relevant empirical coefficients in the model based on more experimental tests, to more accurately predict the coupled in-line and cross-flow VIV response of real-scale deep-water marine drilling risers. It should be noted that, in engineering practice, the in-line and cross-flow VIV response of marine drilling risers is determined by a combination of many factors. In different situations, the influence level of the variation of a specific factor on the VIV response of risers is different. Even in the same situation, the influence level of the variation of a specific factor on the in-line and cross-flow VIV response of risers is not the same. In this paper, the in-line and cross-flow VIV response of a particular marine drilling riser is discussed only in a few situations. In the future, we will systematically analyze the in-line and cross-flow VIV response of different risers under different situations, to provide a basis for the engineering design of deep-water marine drilling risers. 


\section{Data Availability}

All data used to support the findings of this study are included in the article. The data included in this study are available upon request by contacting the corresponding author.

\section{Conflicts of Interest}

The authors declare no potential conflicts of interest with respect to the research, authorship, and/or publication of this article.

\section{Acknowledgments}

The authors gratefully acknowledge the support from the National High Technology Research and Development Program of China (Grant no. 2013AA092602) and the Fundamental Research Funds for the Central Universities (Grant no. 16CX06015A).

\section{References}

[1] X. Wu, F. Ge, and Y. Hong, "A review of recent studies on vortex-induced vibrations of long slender cylinders," Journal of Fluids and Structures, vol. 28, no. 1, pp. 292-308, 2012.

[2] K.-S. Hong and U. H. Shah, "Vortex-induced vibrations and control of marine risers: a review," Ocean Engineering, vol. 152, pp. 300-315, 2018.

[3] R. E. D. Bishop and A. Y. Hassan, "The lift and drag forces on a circular cylinder oscillating in a flowing fluid," Proceedings of the Royal Society of London. Series A. Mathematical and Physical Sciences, vol. 227, no. 1368, pp. 51-75, 1964.

[4] S. Krenk and S. R. K. Nielsen, "Energy balanced double oscillator model for vortex-induced vibrations," Journal of Engineering Mechanics, vol. 125, no. 3, pp. 263-271, 1999.

[5] M. L. Facchinetti, E. de Langre, and F. Biolley, "Coupling of structure and wake oscillators in vortex-induced vibrations," Journal of Fluids and Structures, vol. 19, no. 2, pp. 123-140, 2004.

[6] N. Srinil and H. Zanganeh, "Modelling of coupled cross-flow/ in-line vortex-induced vibrations using double Duffing and van der Pol oscillators," Ocean Engineering, vol. 53, pp. 83-97, 2012.

[7] A. Farshidianfar and N. Dolatabadi, "Modified higher-order wake oscillator model for vortex-induced vibration of circular cylinders," Acta Mechanica, vol. 224, no. 7, pp. 1441-1456, 2013.

[8] X. Bai and W. Qin, "Using vortex strength wake oscillator in modelling of vortex induced vibrations in two degrees of freedom," European Journal of Mechanics-B/Fluids, vol. 48, no. 6, pp. 165-173, 2014.

[9] Y. Jin and P. Dong, "A novel wake oscillator model for simulation of cross-flow vortex induced vibrations of a circular cylinder close to a plane boundary," Ocean Engineering, vol. 117, pp. 57-62, 2016.

[10] Z. Kang, C. Zhang, and R. Chang, "A higher-order nonlinear oscillator model for coupled cross-flow and in-line VIV of a circular cylinder," Ships and Offshore Structures, vol. 13, no. 5, pp. 488-503, 2018.

[11] S. Srinivasan, V. D. Narasimhamurthy, and B. S. V. Patnaik, "Reduced order modeling of two degree-of-freedom vortex induced vibrations of a circular cylinder," Journal of Wind
Engineering and Industrial Aerodynamics, vol. 175, pp. 342351, 2018.

[12] G. Stabile, H. G. Matthies, and C. Borri, "A novel reduced order model for vortex induced vibrations of long flexible cylinders," Ocean Engineering, vol. 156, pp. 191-207, 2018.

[13] M. A. A. Rahman, W. N. Wan Hussin, M. H. Mohd, F. N. Harun, L. K. Quen, and J. K. Paik, "Modified wake oscillator model for vortex-induced motion prediction of low aspect ratio structures," Ships and Offshore Structures, vol. 14, no. s1, pp. s335-s343, 2019.

[14] F. Ge, X. Long, L. Wang, and Y. Hong, "Flow-induced vibrations of long circular cylinders modeled by coupled nonlinear oscillators," Science in China Series G: Physics, Mechanics and Astronomy, vol. 52, no. 7, pp. 1086-1093, 2009.

[15] H. Zanganeh and N. Srinil, "Three-dimensional VIV prediction model for a long flexible cylinder with axial dynamics and mean drag magnifications," Journal of Fluids and Structures, vol. 66, pp. 127-146, 2016.

[16] W. Yang, Z. Ai, X. Zhang, X. Chang, and R. Gou, "Nonlinear dynamics of three-dimensional vortex-induced vibration prediction model for a flexible fluid-conveying pipe," International Journal of Mechanical Sciences, vol. 138-139, pp. 99-109, 2018.

[17] X. M. Li, H. Y. Guo, and F. S. Meng, "Nonlinear coupled inline and cross-flow vortex-induced vibration analysis of top tensioned riser," China Ocean Engineering, vol. 24, no. 7, pp. $749-758,2010$.

[18] F. Ge, W. Lu, L. Wang, and Y.-S. Hong, "Shear flow induced vibrations of long slender cylinders with a wake oscillator model," Acta Mechanica Sinica, vol. 27, no. 3, pp. 330-338, 2011.

[19] J. Gu, Y. Wang, Y. Zhang, M. Duan, and C. Levi, "Analytical solution of mean top tension of long flexible riser in modeling vortex-induced vibrations," Applied Ocean Research, vol. 41, pp. 1-8, 2013.

[20] Y. Komachi, S. Mazaheri, and M. R. Tabeshpour, "Wake and structure model for simulation of cross-flow/in-line vortex induced vibration of marine risers," Journal of Vibroengineering, vol. 20, no. 1, pp. 152-164, 2018.

[21] L. Wang, T. L. Jiang, H. L. Dai, and Q. Ni, “Three-dimensional vortex-induced vibrations of supported pipes conveying fluid based on wake oscillator models," Journal of Sound and Vibration, vol. 422, pp. 590-612, 2018.

[22] R. Gou, X. Zhang, W. Yang, X. Chang, and S. Lu, "Nonlinear dynamics of three-dimensional prediction model for a flexible riser under linearly sheared currents," Arabian Journal for Science and Engineering, vol. 44, no. 2, pp. 829-844, 2019.

[23] Y. Gao, L. Zou, Z. Zong, S. Takagi, and Y. Kang, "Numerical prediction of vortex-induced vibrations of a long flexible cylinder in uniform and linear shear flows using a wake oscillator model," Ocean Engineering, vol. 171, pp. 157-171, 2019.

[24] T. Leclercq and E. de Langre, "Vortex-induced vibrations of cylinders bent by the flow," Journal of Fluids and Structures, vol. 80, pp. 77-93, 2018.

[25] Y. Wang, W. M. Chen, and M. Lin, "Variation of added mass and its application to the calculation of amplitude response for a circular cylinder," China Ocean Engineering, vol. 21, no. 3, pp. 429-437, 2007.

[26] K. H. Aronsen, "An experimental investigation of in-line and combined in-line and cross-flow vortex induced vibrations," Doctoral thesis, Norwegian University of Science and Technology, Trondheim, Norway, 2007.

[27] C. M. Larsen, H. Lie, E. Passano et al., VIVANA Theory Manual (Version3.7), Norwegian Marine Technology Research Institute, Trondheim, Norway, 2009. 
[28] Y. Yuan, H. Xue, and W. Tang, "An improved time domain coupled model of cross-flow and in-line vortex-induced vibration for flexible risers," Ocean Engineering, vol. 136, pp. 117-128, 2017.

[29] L. Song, S. Fu, J. Cao, L. Ma, and J. Wu, “An investigation into the hydrodynamics of a flexible riser undergoing vortex-induced vibration," Journal of Fluids and Structures, vol. 63, pp. 325-350, 2016.

[30] G. R. Franzini, C. P. Pesce, R. T. Gonçalves, A. C. Fujarra, and P. Mendes, "Experimental investigations on vortex-induced vibrations with a long flexible cylinder. Part II: effect of axial motion excitation in a vertical configuration," in Proceedings of the 11th International Conference on Flow-Induced Vibration, Hague, Netherlands, July 2016.

[31] Y. Yuan, H. Xue, and W. Tang, "A numerical investigation of vortex-induced vibration response characteristics for long flexible cylinders with time-varying axial tension," Journal of Fluids and Structures, vol. 77, pp. 36-57, 2018.

[32] M. M. Zhang, S. X. Fu, H. J. Ren, R. P. Li, and L. J. Song, "A time domain prediction method for vortex-induced vibrations of a flexible pipe with time-varying tension," in Proceedings of the ASME 37th International Conference on Ocean, Offshore and Arctic Engineering, Madrid, Spain, June 2018.

[33] X. D. Zhang, R. Y. Gou, W. Y. Yang, and X. P. Chang, "Vortex-induced vibration dynamics of a flexible fluid-conveying marine riser subjected to axial harmonic tension," Journal of the Brazilian Society of Mechanical Sciences and Engineering, vol. 40, no. 8, p. 365, 2018.

[34] F. He, H. Dai, and L. Wang, "Vortex-induced vibrations of a pipe subjected to unsynchronized support motions," Journal of Marine Science and Technology, vol. 23, no. 4, pp. 978-990, 2018.

[35] G. L. Kuiper, J. Brugmans, and A. V. Metrikine, "Destabilization of deep-water risers by a heaving platform," Journal of Sound and Vibration, vol. 310, no. 3, pp. 541-557, 2008.

[36] H. Fan, C. Li, Z. Wang, L. Xu, Y. Wang, and X. Feng, "Dynamic analysis of a hang-off drilling riser considering internal solitary wave and vessel motion," Journal of Natural Gas Science and Engineering, vol. 37, pp. 512-522, 2017.

[37] H. Lie and K. E. Kaasen, "Modal analysis of measurements from a large-scale VIV model test of a riser in linearly sheared flow," Journal of Fluids and Structures, vol. 22, no. 4, pp. 557-575, 2006.

[38] A. D. Trim, H. Braaten, H. Lie, and M. A. Tognarelli, "Experimental investigation of vortex-induced vibration of long marine risers," Journal of Fluids and Structures, vol. 21, no. 3, pp. 335-361, 2005. 